\title{
МЕХАНИЗМЫ СОВЕРШЕНСТВОВАНИЯ ДЕМОГРАФИЧЕСКОЙ ПОЛИТИКИ НА СОВРЕМЕННОМ ЭТАПЕ РАЗВИТИЯ РФ
}

\section{(c) 2021 Джамалудинова Мадинат Юнускадиевна}

кандидат экономических наук, доцент кафедры «Государственное и муниципальное управление» Дагестанский государственный университет, Россия, Респ. Дагестан, Махачкала

E-mail: madina0880@mail.ru

\section{(c) 2021 Асриянц Каринэ Геннадьевна}

кандидат экономических наук, доцент кафедры «Государственное и муниципальное управление» Дагестанский государственный университет, Россия, Респ. Дагестан, Махачкала E-mail:divikas@mail.ru

\section{(c) 2021 Алхасов Запир Мухтарович}

кандидат экономических наук, доцент кафедры «Государственное и муниципальное управление» Дагестанский государственный университет, Россия, Респ. Дагестан, Махачкала

E-mail: divikas@mail.ru

Важность и значимость демографической проблемы признана всеми государствами. Все страны имеют право на развитие, которое уважает границы планеты, обеспечивает устойчивые модели производства и потребления и помогает стабилизировать численность мирового населения. В конечном пространстве рост населения не может быть бесконечным. Стабилизация населения является фундаментальным требованием для прекращения разрушения природных ресурсов и обеспечения удовлетворения основных потребностей каждого человека.

Ключевые слова: демографическая ситуация, население, программы развития, само занятость, трудоспособный возраст.

Нынешнюю демографическую ситуацию в России обычно называют кризисной. Однако более строгие определения не редкость даже до катастрофы. Россия столкнулась с демографическим кризисом, поскольку население страны ежегодно сокращается и стареет, а число смертей превышает рождаемость. Россию, как и весь остальной развитый мир, настигает ошеломляющая демографическая трансформация, называемая глобальным старением.

Конкретно это означает, что больше взрослых вынуждены тратить часы на уход за престарелыми, больше налогов на пенсии и медицинское обслуживание, а также более низкий уровень жизни пожилых людей.

Есть еще одна потенциальная цена тяжелого старения: макроэкономическая дисфункция. Согласно стандартной макроэкономической теории, в каждой стране есть естественная процентная ставка; когда процентные ставки остаются выше этого естественного уровня, страна впадает в дефляцию. Поскольку естественный уровень связан с будущим общим темпом роста страны, большинство теорий сходятся во мне- нии, что низкий прирост населения снижает естественный уровень и затрудняет предотвращение дефляции центральным банкам [1, C.4].

Старение также может иметь еще одно слабое коррозионное воздействие на производительность. Особенно в таких странах, как Россия, которые продвигают людей по старшинству, нехватка динамичных, свежо мыслящих молодых людей может сделать компании менее гибкими и менее открытыми для новых идей. Уменьшение численности населения также подрывает экономическую агломерацию, затрудняя поддержание сети растущих и продуктивных городов.

Более пожилое и сокращенное население, что означает относительно большее количество пенсионеров, меньшую рабочую силу и сокращение налогового пула, связанного с рабочей силой, также указывает на проблему финансирования систем социального обеспечения.

До середины двадцатого века увеличение продолжительности жизни в основном объяснялось снижением смертности от инфекционных заболеваний, от которых страдают как молодые, 
так и пожилые. С тех пор преобладающие причины смертности сместились с инфекционных болезней на хронические, от которых страдают в основном пожилые люди. По мере развития этого так называемого эпидемиологического перехода прогресс в снижении смертности также все больше концентрируется на пожилых людях. В результате шансы прожить от шестидесяти до восьмидесяти или от восьмидесяти до ста теперь улучшаются быстрее, чем шансы прожить от двадцати до сорока или от сорока до шестидесяти, которые и без того очень высоки.

По мере старения населения государственные расходы на здравоохранение, долгосрочное лечение и пенсии естественно возрастают. Но в контексте сокращения расходов, когда количество активной, платящей налоги рабочей силы сокращается, финансирование этого роста государственных расходов может быть проблематичным [4, С. 70].

В рамках Федеральной службы государственной статистики представлен сборник «О социальном положении и уровне жизни населения России» различных годов, наиболее полно отражающий социальные процессы и условия жизни населения России.

Цель демографической политики - это стабилизация численности населения. Преимущества уже исполненных задач демографической политики страны во многом зависит от успешного социально-экономического развития, включая процветание населения, сокращение бедности. Среди второстепенных, но не менее важных факторов: дифференциация доходов, интенсивно развивающееся создание человеческого капитала, эффективной социальной инфраструктуры, доступного рынка личной недвижимости, гибкого рынка труда, улучшения эпидемиологической ситуации [4, С. 70].

Стратегии и проекты по демографической ситуации может иметь тенденцию к упрощению, фокусируясь на размере населения, а не на качественных аспектах, составляющих человеческий капитал, таких как образование или здоровье. Это представляет собой фундаментальную проблему при обсуждении стратегии, которая иногда может казаться устаревшей.

Показатели, характеризующие различные аспекты уровня жизни населения, объединены в тематические разделы [2, С. 96].

Выделим ряд используемых показателей, по данным которых появляется возможность су- дить о тенденции развития социальной политики и определить направления реализации демографической проблемы: занятость, безработица и условия труда, денежные доходы населения и их использование, дифференциация доходов и бедность, социальная защита, расходы и потребления домашних хозяйств, жилищные условия, состояние здоровья и медицинское обслуживание населения, образование, культура, туризм и отдых и т.д.

Сборник содержит макроэкономические показатели, отражающие социально-экономическое развитие страны, сведения о демографической ситуации, занятости и безработице, условиях труда, размере и структуре денежных доходов и их распределении по различным социально-экономическим группам населения, уровне оплаты труда, жилищных условиях, состоянии здоровья населения и развитии системы здравоохранения, образовании населения.

Хотя увеличение продолжительности жизни может быть той силой, которая впервые приходит на ум, когда люди думают о старении населения, снижение рождаемости является более важным фактором в количественном отношении.

Дополнительная поддержка семей с детьми в виде оплаты материнского капитала (семейного капитала) на рождение более одного ребенка, усыновленная на 10 лет, показала большую демографическую эффективность и положительно повлияла на улучшение демографической ситуации в ЕС страны [6, С.15].

Более 90\% единовременных выплат по беременности и родам были направлены на сохранение и изменения уровня обустройства жилья. Однако эта мера сыграла особую роль в повышении рождаемости сельского населения, где действительно можно купить жилье на эту сумму. В малых городах он работал хуже, в крупных городах практически не влиял на рождаемость более одного ребенка в семье.

Продление этой меры до 2025 года позволит женщинам (включая женщин от 30 до 44 лет), будет иметь второй и послеродовой потенциал.

В то же время необходимо обратить внимание на разработку мер, направленных на жителей агломераций. Среди данных направления можно выделить, о возможности покупки квартиры без оплаты после рождения третьего ребенка [5, С.54].

Должны быть созданы максимально ком- 
фортные условия для женщин или отцов (в виде отпусков и выходных дней), чтобы они могли совмещать обязанности по воспитанию детей с работой, обеспечивать гибкий график работы, регулярно повышать свою квалификацию и заниматься переработкой отходов.

Особое внимание следует уделить повышению качества жизни и уровня жизни населения. Индикаторы социального статуса и социального развития - это совокупность объективных и субъективных показателей, отражающих эффективность социального воспроизводства населения, социальные предпочтения, моральные ценности и установки людей, получаемых путем анализа социальной статистики и во время региона и экспертов, а также индикаторы, характеризующие аспекты наиболее острых нерешенных вопросов в регионе.

На проблему устойчивого развития особое влияние оказывает национальная безопасность. Разрабатывая ту или иную экономическую, политическую или экологическую программу безопасности, необходимо иметь в виду тот факт, что производимый эффект от данной программы должен способствовать трансформации страны и ее регионов в сторону устойчивого развития. Под этим понимается укрепление власти и самого государства, совершенствование процесса устойчивого социально-экономического развития [3, С. 134].

Доступ к медицинскому обслуживанию уменьшился, что значительно ощутило сельское население. Многие дети заболели из-за плохого питания. Лучше в данной области отражены меры, принятые для предотвращения этих проблем. Предлагается, широко развивать культуру сбалансированного потребления пищи в социальных медиа платформах, организовывать более качественную маркировку продуктов, предлагать бесплатное горячее питание в учебных заведениях и обеспечивать дополнительное питание детей из малообеспеченных семей [1, С. 10].

Необходимо активировать социальные инструменты при формировании моделей социального поведения и привлечь внимание к социальным проблемам, например: пропагандировать здоровый образ жизни, бороться с наркотиками, соблюдать правила дорожного движения и т.д.

Этот аспект определяет разработку системы мер по поддержанию трудового потенциала страны. Перспективы повышения рождаемости выглядят туманными. Более того, даже если бы уровень рождаемости резко увеличился в одночасье, это не оказало бы заметного влияния на соотношение работающих и пенсионеров или темпы роста занятости в течение следующих двадцати-двадцати пяти лет, времени, необходимого для того, чтобы превратить новорожденного ребенка. в полноценного взрослого человека. Перспективы увеличения чистой иммиграции также выглядят туманными и, вероятно, станут еще более слабыми после нынешней пандемии [2, С.96].

Однако демографические меры, принятые руководящими должностями Российской Федерации, дадут результаты только в будущем. Поэтому только миграция компенсирует демографический спад населения в ближайшие годы.

Учитывая растущую роль миграции в российском обществе, необходимо создать комплексную систему регулирования миграции, которая поможет достичь и поддерживать баланс интересов между мигрантами и принимающей стороной.

Поскольку иммигранты в среднем моложе коренного населения, они могут стимулировать рост занятости и тормозить старение населения. Но иммигранты в свою очередь имеют досадную привычку стареть, Это означает, что разовое увеличение чистой иммиграции мало что изменит в долгосрочной возрастной структуре населения. Для замедления старения населения за счет увеличения иммиграции требуется не только постоянное увеличение чистой иммиграции, но и рост, который продолжает расти с течением времени. Что касается продолжительности жизни, мы все должны надеяться, что она возобновит свой рост [5, С.54].

Приняв более активную политику в области образовательных миграционных процессов, Россия сможет значительно повысить уровень контроля над иммигрантами и, прежде всего, над молодыми гражданами требуемых областей, которые знают язык и интегрированы в общество.

Поэтому имеется необходимость разработки и реализации целевой программы управления образовательной миграцией в Российской Федерации [3, С.137].

Особое значение приобретает вопрос регулирования внутренней миграции в стране. Для повышения эффективности этих мер, с одной стороны, необходимо обеспечить разработку и 
принятие региональных программ регулирования мобильности населения с учетом территориальной дифференциации рынка общественного транспорта. ситуационные и демографические процессы и др. переселение и занятость в отдельных регионах подлежат уточнению [2, С.97].

Безусловно, старение всегда влечет за собой дополнительную финансовую нагрузку. Старые обязательно потребляют больше медицинских услуг и услуг по долгосрочному уходу, чем молодые, и независимо от того, как долго люди продолжают работать, наступает время, когда почти каждый либо хочет, либо должен выйти на пенсию. Точно так же старение всегда влечет за собой некоторое замедление экономического роста. Но величина дополнительного бремени и степень сопротивления будут зависеть от политического выбора.

Таким образом, если не будут приняты но- вые меры для поддержания рождаемости, предотвращения смертности и регулирования миграции, население будет сокращаться. Расчеты показывают, что, несмотря на достигнутые улучшения, население России в ближайшие десятилетия будет стремительно сокращаться, несмотря на сохранение нынешнего уровня рождаемости - до 138,5 миллиона человек в 2020 году и 112,4 миллиона человек в 2050 году.

В будущем территориальная гибкость населения возрастет, особенно в восточных регионах страны. В то же время в районах с низкой рождаемостью интенсивность перемещения населения к месту назначения поселка-городка может снизиться, тем более что резервы возможных переселенцев в этих районах невелики. В целом демографическая ситуация в нашей стране очень разная.

\section{Библиографический список}

1. Архангельский В.Н., Иванова А.Е. и др. Стратегия демографического развития России / Под ред. Кузнецова В.Н. и Рыбаковского Л. Л. . М., 2014.

2. Байбурина Р.Ф. Демографическая политика Российской Федерации // Молодой ученый. - 2020.- С. 95-97.

3. Джамалудинова М.Ю., Хизриева С. К. Управление мотивацией к труду работников организаций. // Актуальные проблемы в современной науке и пути их решения. Экономические науки. 2016. № 5(26). С.134-139.

4. Джамалудинова М.Ю., Асриянц К. Г. Особенность безработицы в Российской Федерации: проблемы и развитие.// РИСК: ресурсы, информация, снабжение, конкуренция».2017. № 4.- С.69-72.

5. Курдова М.А. Современная демографическая политика в России и пути ее реализации / М.А.Курдова, О.Г.Ефимова // Экономика и бизнес: теория и практика.- 2018.- № 2.- С. 51-55.- Электронная копия доступна на сайте науч. Электрон. Б-ки КиберЛенинка. URL: https://cyberleninka.ru/article/n/sovremennayademograficheskaya-politika-v-rossii-i-puti-ee-realizatsii-1

6. Подлужная М.Я. Постарение населения - характерная составляющая современных демографических процессов / М.Я.Подлужная, Е.А.Воронова, Н.В.Исаева, Э.А.Рудакова // Пермский медицинский журнал.2018. 